\title{
PENERAPAN LEAN WAREHOUSE PADA GUDANG PRODUK JADI CV. BUMI MAKMUR, KARANG TENGAH, WONOGIRI UNTUK MEMINIMASI PEMBOROSAN
}

\author{
Ida Nursanti dan Febriana Musfiroh \\ Jurusan Teknik Industri, Fakultas Teknik, Universitas Muhammadiyah Surakarta \\ Jl. A Yani Tromol Pos I Pabelan, Surakarta. \\ e-mail: Ida.Nursanti@ums.ac.id
}

\begin{abstract}
ABSTRAK
Peningkatan kinerja harus dilakukan secara terus menerus pada semua lini proses produksi agar dapat meminimalisir pemborosan yang terjadi salah satuya yaitu dengan menerapkan lean warehouse. Penelitian ini dilakukan pada gudang milik CV. Bumi Makmur yang merupakan produsen bahan baku cincau atau janggelan di wonogiri. Tujuan dari penelitian yaitu mengetahui jenis waste apa saja yang terdapat di gudang, mengidentifikasi dan menganalisis waste yang memiliki nilai tertinggi, kemudian mengurangi pemborosan tersebut. Big Picture Mapping digunakan untuk memetakan secara visual dan menganalisis waste yang terjadi pada aliran proses produksi di gudang. Untuk mengetahui waste yang paling banyak terjadi digunakan kuesioner dan didapatkan waste dengan nilai tertinggi yaitu waste jenis over production di gudang 1 dan waste jenis defects di gudang 2 yang selanjutnya di identifikasi penyebab masalahnya menggunakan fishbone diagram. Untuk meminimalisir waste yang terjadi dilakukan perbaikan dengan melakukan penerapan 5S (Seiri, Seiton, Seiso, Seiketsu, Shitsuke), setelah dilakukan penerapan diperoleh hasil yang cukup baik, dari hasil inspeksi terdapat pengurangan temuan ketidaksesuaian dari kategori Red sebanyak 13 temuan menjadi White sebanyak 3 temuan. Kemudian dilakukan pengukuran ulang waktu alur proses di gudang setelah penerapan 5 S didapatkan pengurangan waktu sebesar 3 jam 10 menit 35 detik.
\end{abstract}

Kata kunci: Waste, Lean Warehouse, Gudang, $5 S$

\begin{abstract}
Performance improvement must be done continuously on all production process lines in order to minimize waste that happened by applying lean warehouse. This research was conducted on the warehouse of CV. Bumi Makmur which is a producer of raw materials of grass jelly in Wonogiri. The purpose of the research was to know what kind of waste occurred in the warehouse, identify and analyse the waste that has the highest value, then reduce the waste. Big Picture Mapping was used to map visually and analyse the waste that occurs in the production process flow in the warehouse. To find out the most waste occurs used questionnaires and obtained waste with the highest value. The result shows that the most waste that happens in the first and second warehouse was over production and defect respectively. Furthermore, the cause of the problem identified using a fishbone diagram and 5S (Seiri, Seiton, Seiso, Seiketsu, Shitsuke) method was used to minimize the waste. The application of 5S method obtained a good result, there was a reduction of findings of nonconformity from the Red category as much as 13 findings to White as many as 3 findings. Moreover, the processing time was reduced by 3 hours 10 minutes 35 seconds.
\end{abstract}

Keywords: Waste, Lean Warehouse, Warehouse, 5 S

\section{PENDAHULUAN}

Gudang (warehouse) merupakan suatu fungsi penyimpanan berbagai jenis produk yang memiliki unit penyimpanan dalam jumlah besar maupun kecil yang memiliki jangka waktu tertentu dari penyimpanan produk hasil produksi, pemeliharaan produk hingga produk dikeluarkan untuk pelanggan [1]. Gudang memiliki peran sebagai penyangga antara ketidakpastian pasokan dan permintaan sehingga mampu menjaga keseimbangan rantai pasokan dalam aliran produksi. Adapun beberapa aktivitas dasar dalam pergudangan menurut Gergova [2] diantaranya yaitu penerimaan bahan baku ataupun produk jadi yang akan disimpan dalam gudang, penyimpanan bahan baku atau produk jadi sesuai dengan kategori yang ditentukan oleh masing-masing kebijakan gudang, proses pengambilan bahan baku atau produk jadi 
sesuai dengan permintaan. Pengambilan barang dilakukan sesuai dengan kriteria produk dan ketentuan rute masing-masing gudang, dan pengiriman bahan baku atau produk jadi kepada pelanggan sesuai dengan permintaan.

Banyaknya aktivitas yang penting pada gudang membuat perusahaan harus meningkatkan kinerjanya menjadi efektif dan efisien secara terus menerus untuk mempertahankan kepercayaan pelanggan dan meningkatkan mutu perusahaan termasuk pada gudang CV. Bumi Makmur yang merupakan perusahaan yang memproduksi bahan baku janggelan atau cincau hitam yang menjangkau pasar luar negeri diantaranya yaitu Malaysia, Taiwan, dan China. Terdapat dua gudang yaitu gudang 1 dan gudang 2, kedua gudang ini digunakan untuk melakukan packing bahan baku janggelan kering, penyimpanan produk jadi hingga produk jadi siap dikirim kepada konsumen.

Terdapat 7 (tujuh) jenis pemborosan (waste) yang biasa disebut dengan TIMWOOD [3]. Dan dari observasi yang dilakukan di CV. Bumi Makmur terdapat beberapa waste yang ditemukan seperti over production terjadi saat permintaan perusahaan meningkat yang mengakibatkan bahan baku serta produk jadi memakan tempat dan mulai mengganggu aliran proses di gudang, produk cacat (defects) yang ditemukan oleh customer ataupun defects yang ditemukan petugas saat pemindahan produk ke truk pengiriman sehingga menimbulkan biaya tambahan untuk membongkar ulang produk yang rusak dan tidak sesuai permintaan. Untuk mengetahui secara detail waste yang terjadi maka perlu dilakukan penelitian lebih lanjut yaitu dengan melakukan penerapan lean warehouse. Penerapan value stream mapping untuk mengidentifikasi waste telah dilakukan oleh Barros [4] pada gudang komponen otomotif serta oleh Purnomo dan Bisono [5] di gudang pabrik rokok. Sebelumnya, Chen dkk. [6] menggunakan lean dan RFID untuk warehouse management, sedangkan Sharma dan Shah [7] menggunakan RTD dan ANP untuk menjalankan lean warehouse. Perbedaan penelitian ini dengan yang sebelumnya adalah objek penelitiannya serta metode yang digunakan untuk menghasilkan lean warehouse yaitu metode 5S.

\section{METODE PENELITIAN}

Untuk mengidentifikasi waste yang terjadi pada proses pergudangan digunakan Big Picture Mapping. Selanjutnya TIMWOOD assessment [8] digunakan untuk pembobotan waste yang harus dihilangkan terlebih dahulu dengan menyebarkan kuesioner kepada pekerja di gudang 1 dan gudang 2 masing-masing 6 orang, kemudian dilakukan pembobotan nilai dari semua kuesioner yang didapat. Untuk menganalisis penyebab terjadinya pemborosan (waste), fishbone diagram digunakan dan perbaikan sistem dilakukan dengan menerapkan metode 5S (Seiri, Seiton, Seiso, Seiketsu, Shitsuke).

\section{HASIL DAN PEMBAHASAN Big Picture Mapping}

Big picture mapping dari proses pergudangan di CV. Bumi Makmur dapat dilihat pada Gambar 1 dan Gambar 2.

Dari big picture mapping gudang 1 dan 2 pada Gambar 1 dan Gambar 2 dapat dilihat aliran proses apa saja yang terdapat pada gudang serta waktu yang dibutuhkan dalam setiap proses yang terjadi di gudang. Beberapa contoh pemborosan (waste) yang terjadi di gudang 1 dan 2 adalah sebagai berikut:

a. Terdapat waste dari over production di gudang, dilihat dari data jumlah produksi pada bulan Agustus 2016 gudang 1 dan 2 menghasilkan selisih jumlah produksi dengan jumlah pengiriman produk jadi sebanyak 80 pack gudang 1 dan 38 pack untuk gudang 2 setiap bulannya. Dapat dilihat bahwa gudang 1 dan 2 memproduksi janggelan melebihi permintaan konsumen dan menghasilkan inventory yang menumpuk setiap bulannya.

b. Defects yang terjadi pada gudang yaitu kecacatan produk yang terjadi pada finished goods diantaranya timbulnya jamur dan kotoran pada produk jadi pada gudang persediaan.

c. Unnecessary Inventory disebabkan adanya over production yang terjadi pada gudang, baik persediaan bahan baku maupun produk 


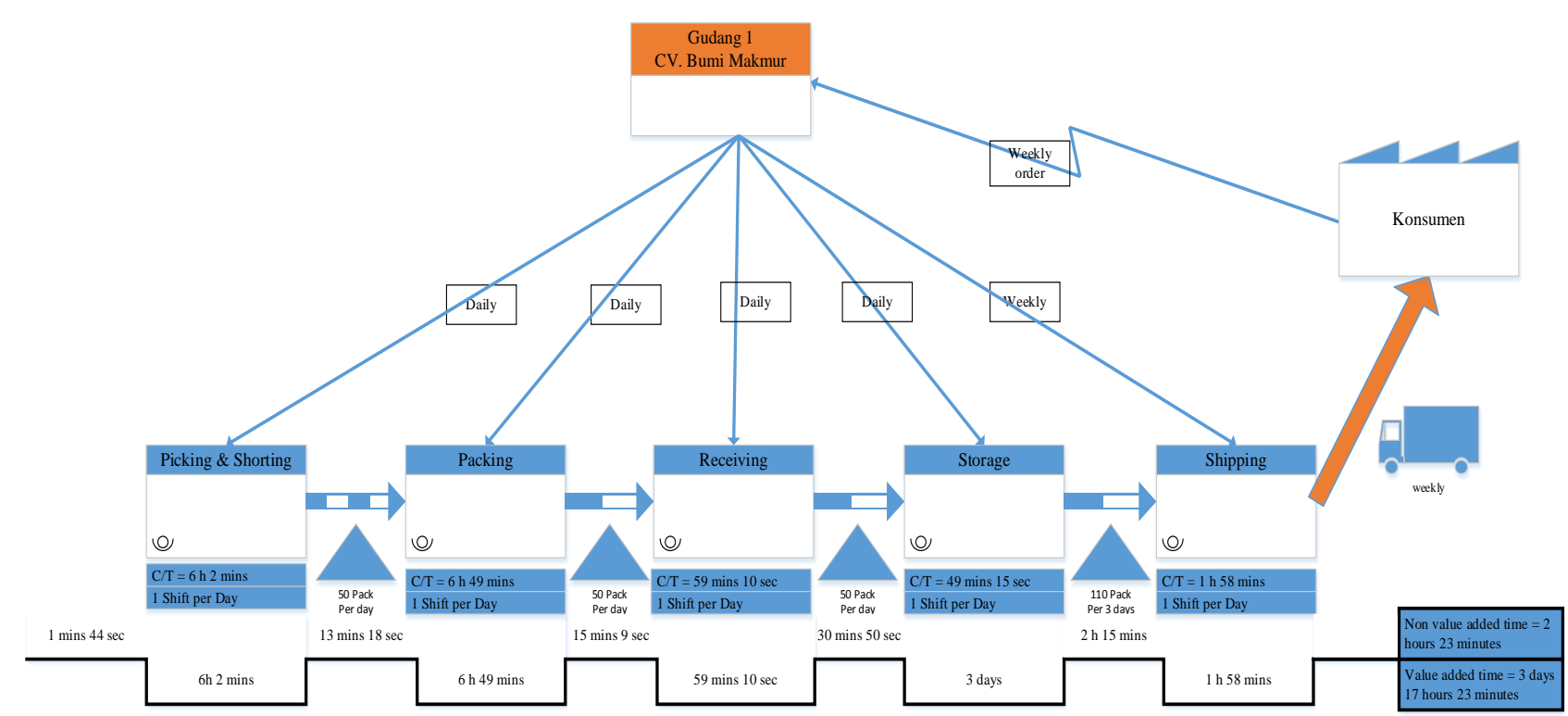

Gambar 1. Big Picture Mapping Gudang 1

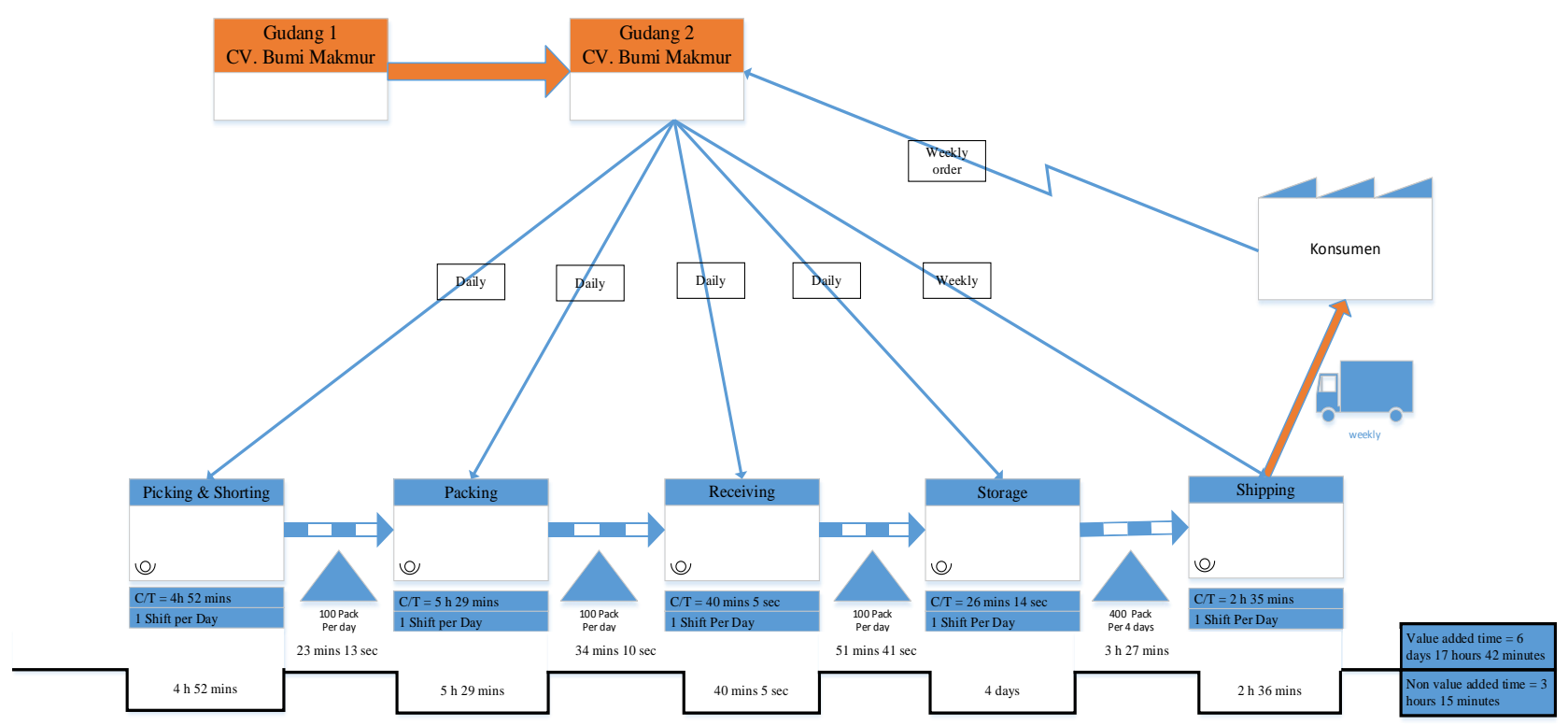

Gambar 2. Big Picture Mapping Gudang 2

jadi. Kelebihan persediaan ini menimbulkan aktivitas penanganan tambahan seperti sumber daya tambahan untuk menangani penumpukan produk pada gudang.

d. Inappropriate processing pada gudang yaitu penyimpanan produk di gudang memiliki ketentuan FIFO (First In First Out) namun ketentuan ini belum diterapkan secara tertib. Hal ini mengakibatkan saat penyimpanan letak produk masih bercampur sehingga menyebabkan proses yang berlebih saat pemindahan produk.

e. Execessive transportation, Dalam sehari gudang 1 dan 2 menghasilkan produk sebanyak 50-100 pack produk jadi yang harus dipindahkan ke area penyimpanan setiap harinya, dan gudang 2 setiap minggunya melakukan pengiriman produk sebanyak 100 - 400 produk yang harus diangkut oleh pekerja ke truk pengiriman. Hal ini dapat mengakibatkan kelelahan ataupun cidera pada pekerja.

f. Waiting atau waktu tunggu yang diakibatkan oleh adanya keterlambatan penyediaan bahan baku dari gudang 1 ataupun dari pemasok janggelan sehingga dapat membuat jadwal produksi berubah, namun bahan baku akan mengalami 
penumpukan ketika panen raya janggelan membuat bahan baku menunggu waktu pemrosesan.

g. Execessive movement di gudang setiap hari pekerja menata 50-100 pack produk jadi secara manual. Hal ini dapat mengakibatkan kelelahan ataupun cedera pada pekerja karena melakukan aktivitas berulang-ulang seperti membungkuk, mengangkat dan mengatur produk jadi.

\section{TIMWOOD Assesment}

Pada gudang 1 kuesioner diberikan kepada 6 pegawai yang memiliki peran penting dalam semua aktivitas di gudang 1 . Hasil rekap kuesioner yang telah diberikan kepada pekerja dapat dilihat pada Tabel 1.

Dari hasil rekap kuesioner dilakukan pembobotan waste, didapatkan peringkat waste dengan bobot tertinggi yaitu waste dari over production yang dapat dilihat pada Tabel 2 .

Hasil rekap kuesioner yang telah diberikan kepada pekerja pada gudang 2 dapat dilihat pada Tabel 3.

Dari hasil rekap kuesioner dilakukan pembobotan waste, didapatkan peringkat waste dengan bobot tertinggi yaitu waste dari defects yang dapat dilihat pada Tabel 4 .

Tabel 1. Rekap Hasil Kuesioner Gudang 1

\begin{tabular}{llccccccc}
\hline \multirow{2}{*}{ No } & \multirow{2}{*}{ Jenis Pemborosan } & \multicolumn{7}{c}{ Nilai } \\
\cline { 3 - 9 } & & 1 & 2 & 3 & 4 & 5 & 6 & Jumlah \\
\hline 1 & Over production & 1 & 2 & 2 & 2 & 4 & 4 & 15 \\
2 & Defects & 1 & 1 & 3 & 1 & 3 & 3 & 12 \\
3 & Unnecessary Inventory & 1 & 1 & 2 & 1 & 2 & 2 & 9 \\
4 & Inapropriate Processing & 2 & 1 & 1 & 2 & 1 & 1 & 8 \\
5 & Excessive Transportation & 2 & 2 & 1 & 1 & 1 & 1 & 8 \\
6 & Waiting Time & 1 & 2 & 1 & 1 & 1 & 2 & 8 \\
7 & Unnecessary Movement & 1 & 1 & 1 & 1 & 1 & 1 & 6 \\
\hline$\quad$ Total Nilai & & & & & & & 66 \\
\hline
\end{tabular}

Tabel 2. Peringkat Pemborosan (waste) Gudang 1

\begin{tabular}{|c|c|c|c|c|c|c|c|c|c|c|}
\hline \multirow{2}{*}{ No } & \multirow{2}{*}{ Jenis Pemborosan } & \multicolumn{6}{|c|}{ Bobot } & \multirow{2}{*}{ Jumlah } & \multirow{2}{*}{ Bobot } & \multirow{2}{*}{ Peringkat } \\
\hline & & 1 & 2 & 3 & 4 & 5 & 6 & & & \\
\hline 1 & Over production & 1 & 2 & 2 & 2 & 4 & 4 & 15 & 0,22727 & 1 \\
\hline 2 & Defects & 1 & 1 & 3 & 1 & 3 & 3 & 12 & 0,18182 & 2 \\
\hline 3 & Unnecessary Inventory & 1 & 1 & 2 & 1 & 2 & 2 & 9 & 0,13636 & 3 \\
\hline 4 & Inapropriate Processing & 2 & 1 & 1 & 2 & 1 & 1 & 8 & 0,12121 & 4 \\
\hline 5 & Excessive Transportation & 2 & 2 & 1 & 1 & 1 & 1 & 8 & 0,12121 & 5 \\
\hline 6 & Waiting Time & 1 & 2 & 1 & 1 & 1 & 1 & 8 & 0,12121 & 6 \\
\hline 7 & Unnecessary Movement & 1 & 1 & 1 & 1 & 1 & 1 & 6 & 0,09091 & 7 \\
\hline & Total Nilai & & & & & & & 65 & 1 & \\
\hline
\end{tabular}

Tabel 3. Rekap Hasil Kuesioner Gudang 2

\begin{tabular}{|c|c|c|c|c|c|c|c|c|}
\hline \multirow{2}{*}{ No } & \multirow{2}{*}{ Jenis Pemborosan } & \multicolumn{6}{|c|}{ Bobot } & \multirow{2}{*}{ Jumlah } \\
\hline & & 1 & 2 & 3 & 4 & 5 & 6 & \\
\hline 1 & Over production & 1 & 1 & 1 & 2 & 2 & 1 & 8 \\
\hline 2 & Defects & 3 & 1 & 1 & 3 & 3 & 3 & 14 \\
\hline 3 & Unnecessary Inventory & 1 & 1 & 2 & 2 & 1 & 4 & 11 \\
\hline 4 & Inapropriate Processing & 2 & 1 & 1 & 2 & 2 & 1 & 9 \\
\hline 5 & Excessive Transportation & 1 & 2 & 2 & 1 & 1 & 1 & 8 \\
\hline 6 & Waiting Time & 2 & 2 & 1 & 1 & 1 & 2 & 9 \\
\hline 7 & Unnecessary Movement & 1 & 1 & 1 & 2 & 1 & 1 & 7 \\
\hline & Total Nilai & & & & & & & 66 \\
\hline
\end{tabular}


Tabel 4. Peringkat Pemborosan (waste) Gudang 2

\begin{tabular}{|c|c|c|c|c|c|c|c|c|c|c|}
\hline \multirow{2}{*}{ No } & \multirow{2}{*}{ Jenis Pemborosan } & \multicolumn{6}{|c|}{ Bobot } & \multirow{2}{*}{ Jumlah } & \multirow{2}{*}{ Bobot } & \multirow{2}{*}{ Peringkat } \\
\hline & & 1 & 2 & 3 & 4 & 5 & 6 & & & \\
\hline 1 & Over production & 1 & 1 & 1 & 2 & 2 & 1 & 8 & 0,12121 & 5 \\
\hline 2 & Defects & 3 & 1 & 1 & 3 & 3 & 3 & 14 & 0,21212 & 1 \\
\hline 3 & Unnecessary Inventory & 1 & 1 & 2 & 2 & 1 & 4 & 11 & 0,16667 & 2 \\
\hline 4 & Inapropriate Processing & 2 & 1 & 1 & 2 & 2 & 1 & 9 & 0,13636 & 3 \\
\hline 5 & Excessive Transportation & 1 & 2 & 2 & 1 & 1 & 1 & 8 & 0,12121 & 6 \\
\hline 6 & Waiting Time & 2 & 2 & 1 & 1 & 1 & 2 & 9 & 0,13636 & 4 \\
\hline 7 & Unnecessary Movement & 1 & 1 & 1 & 2 & 1 & 1 & 7 & 0,10606 & 7 \\
\hline & Total Nilai & & & & & & & 66 & 1 & \\
\hline
\end{tabular}

\section{Fishbone Diagram}

Dari hasil pembobotan waste pada gudang 1 dan gudang 2 didapatkan jenis pemborosan (waste) yang harus dihilangkan terlebih dahulu yaitu pemborosan dari produksi berlebih (over production) untuk gudang 1 dan pemborosan akibat adanya kecacatan produk (defects) untuk gudang 2. Kedua pemborosan tersebut dianalisis akar permasalahannya menggunakan diagram fishbone yang dijabarkan pada Gambar 3 dan 4.

Dari penyebab-penyebab over production pada Gambar 3. mengakibatkan penumpukan persediaan material maupun produk jadi pada gudang yang harus disimpan melebihi kapasitas gudang memakan tempat yang terlalu banyak sehingga menganggu aliran proses pada gudang, banyaknya inventory mengakibatkan sulitnya pengawasan dan menimbulkan kerusakan produk jadi yang tidak diketahui karena terlalu lama berada di gudang penyimpanan.

Pemborosan dari defect ini terjadi di stasiun penyimpanan yaitu pada produk jadi yang telah siap dikirim. Pada saat pengangkutan produk jadi ke truk pengiriman sering ditemukannya produk cacat seperti karung yang kotor dan berjamur sehingga produk tidak memenuhi kriteria atau tidak layak kirim. Produk cacat harus diproses ulang agar memenuhi kriteria namun akan dibuang apabila sudah tidak dapat diperbaiki kembali.

\section{Metode 5S}

Untuk mereduksi pemborosan (waste) dari produksi berlebih dan defect dilakukan perbaikan dengan menggunakan 5S (Seiri, Seiton, Seiso, Seiketsu, Shitsuke) diantaranya adalah sebagai berikut:

1. Seiri (Ringkas)

Pada Seiri, pertama dilakukan pemilahan barang dan pemilahan produk jadi dan

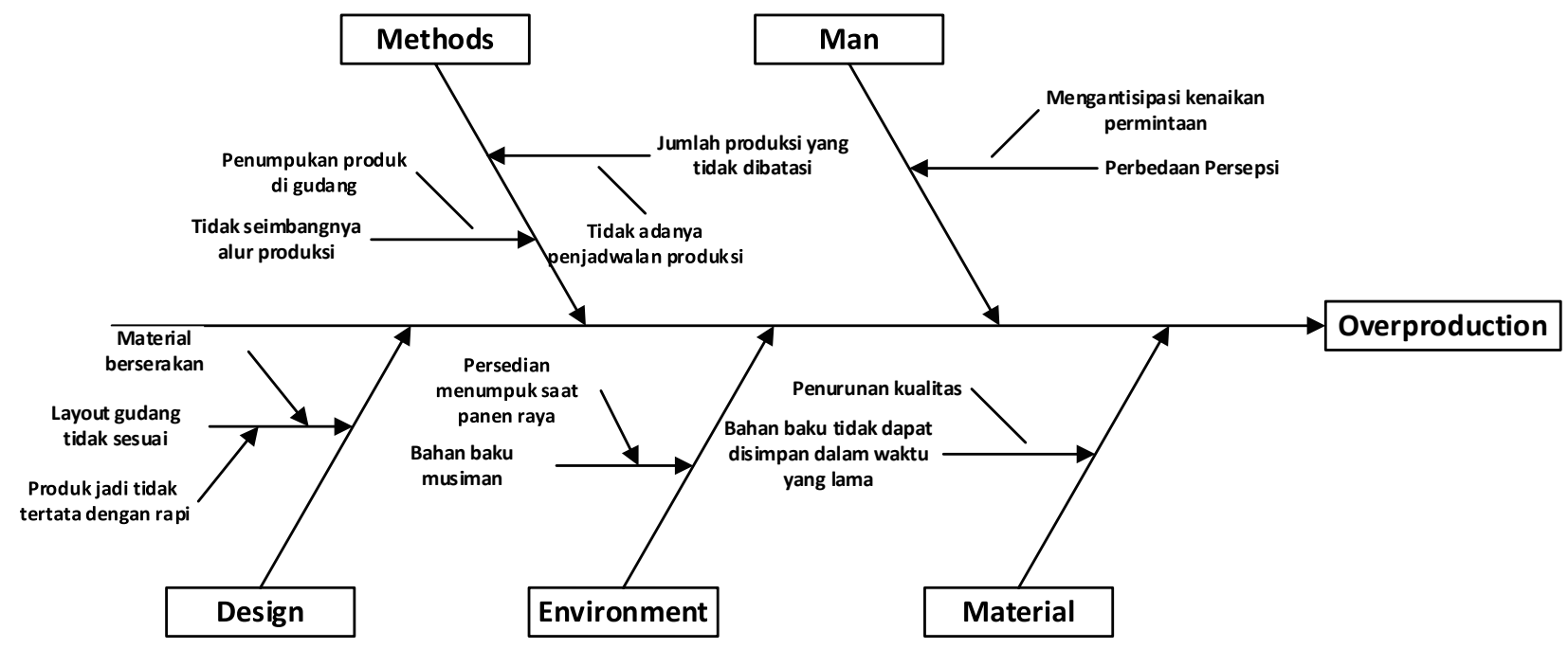

Gambar 3. Fishbone Diagram Over Production 


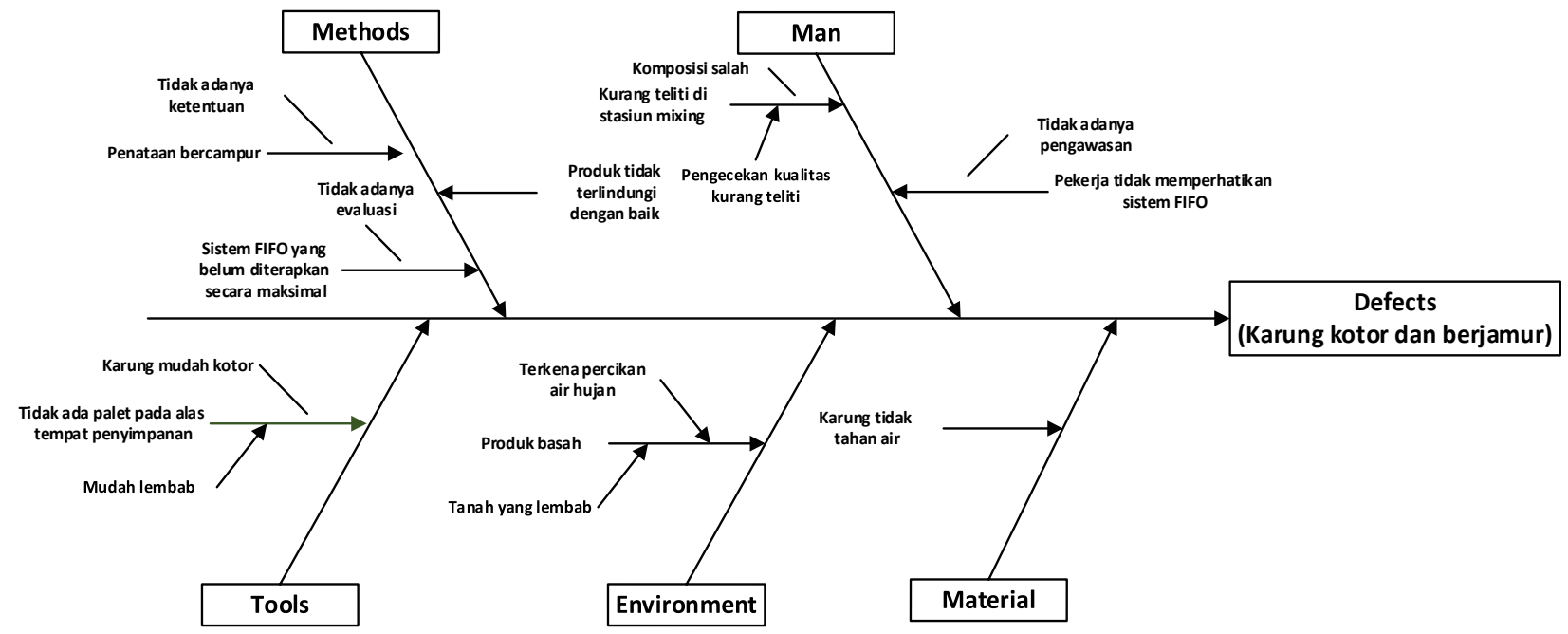

Gambar 4. Fishbone Diagram Defects

pemberian label yang sesuai dengan tanggal produksi. Hasil dokumentasi dapat dilihat pada Gambar 5 dan Gambar 6.

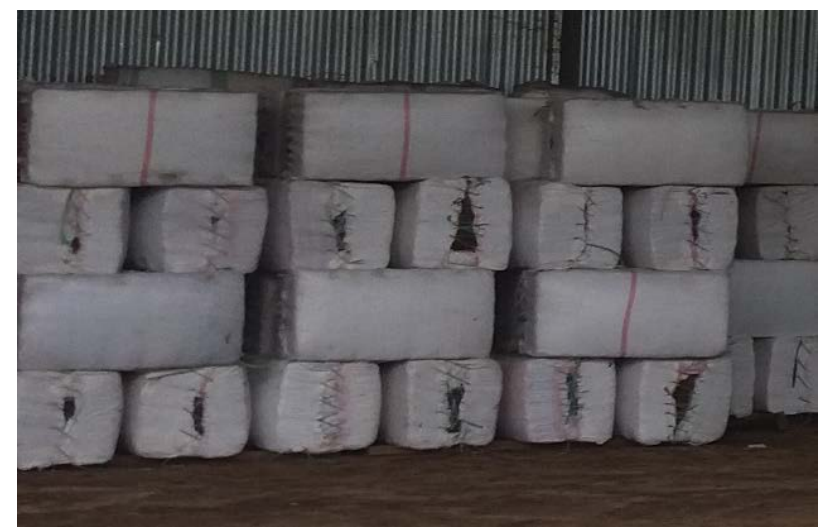

Gambar 5. Sebelum Pemberian Label Produk

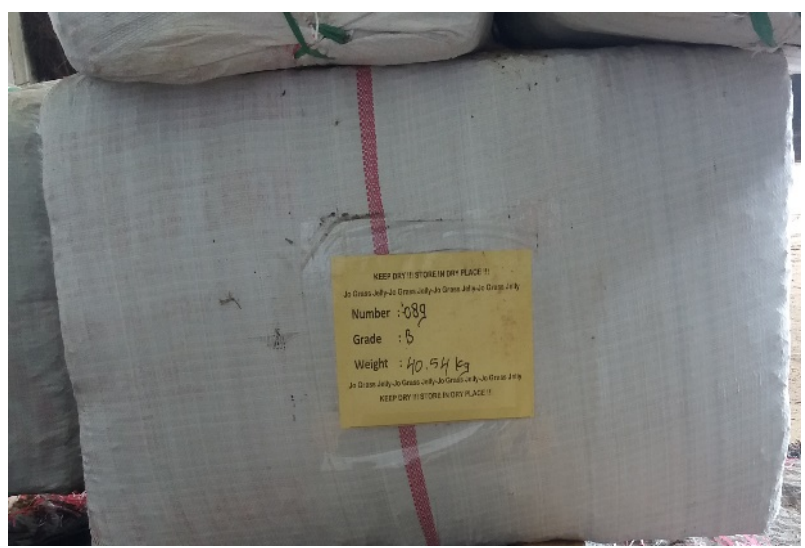

Gambar 6. Sesudah Pemberian Label Produk

Pada label produk berisikan keterangan nomor produk, terdapat 2 warna label yang dibuat yaitu warna kuning untuk pengiriman minggu 1 dan 2, warna merah muda untuk pengiriman minggu ke 3 dan 4 , grade untuk menunjukkan kualitas dari produk terdapat 2 jenis grade yaitu grade $\mathrm{A}$ dan grade $\mathrm{B}$, kemudian weight atau berat untuk berat produk.

2. Seiton (Rapi)

Pada tahap Seiton perbaikan yang dilakukan diantaranya adalah sebagai berikut:

a. Pengelompokkan produk jadi dilakukan sesuai kloter pengiriman untuk memudahkan pekerja saat pengangkutan produk ketika dikirim. Hasil penerapan dapat dilihat pada Gambar 7 dan Gambar 8.

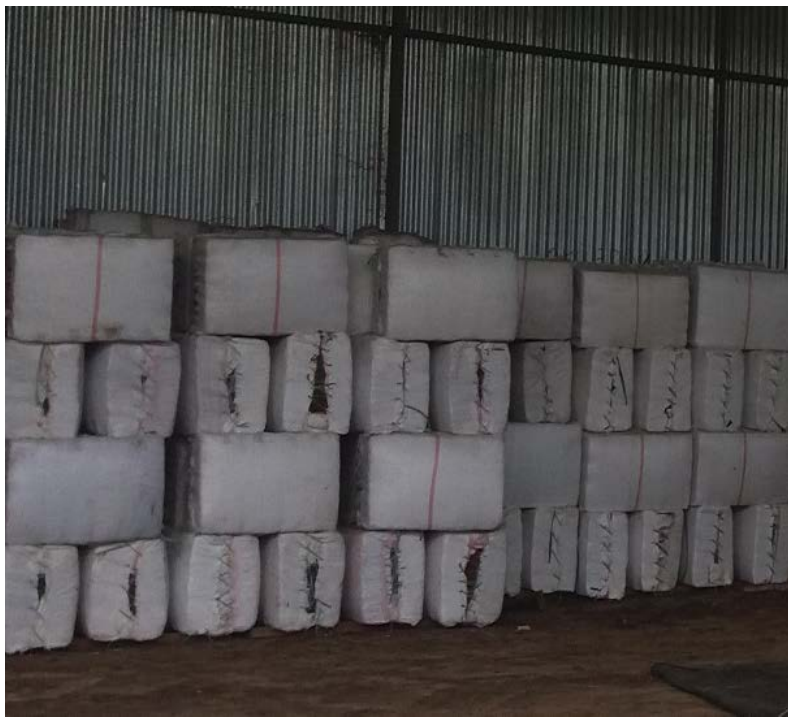

Gambar 7. Sebelum Pengelompokkan Produk Jadi 


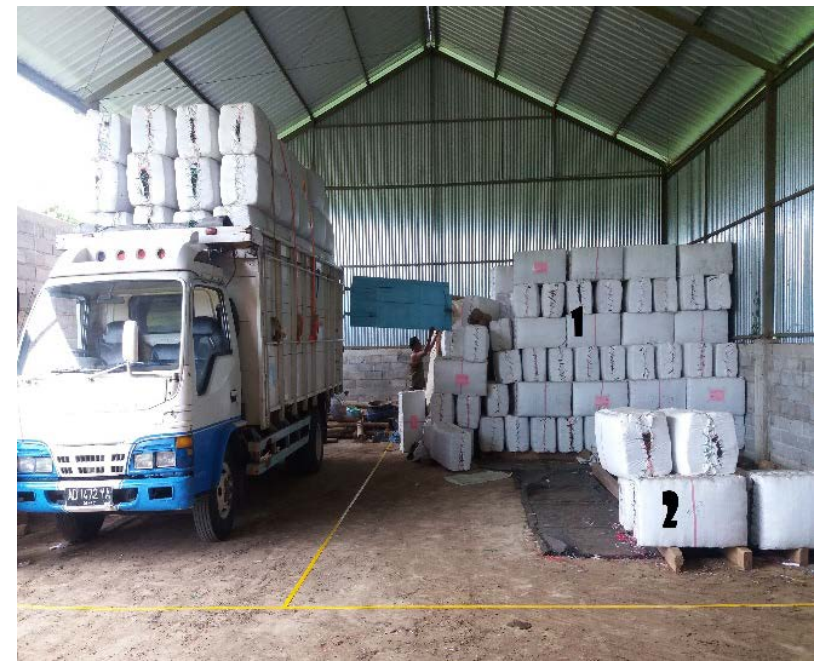

Gambar 8. Sesudah Pengelompokkan Produk Jadi

Keterangan:

No. 1 (Label merah muda): Produk jadi untuk pengiriman minggu 3 dan 4

No. 2 (Label kuning): Produk jadi untuk pengiriman minggu 3 dan 4

b. Penataan palet pada produk jadi untuk menjaga produk agar tidak mudah rusak. Hasil penataan palet dapat dilihat pada Gambar 9 dan Gambar 10.

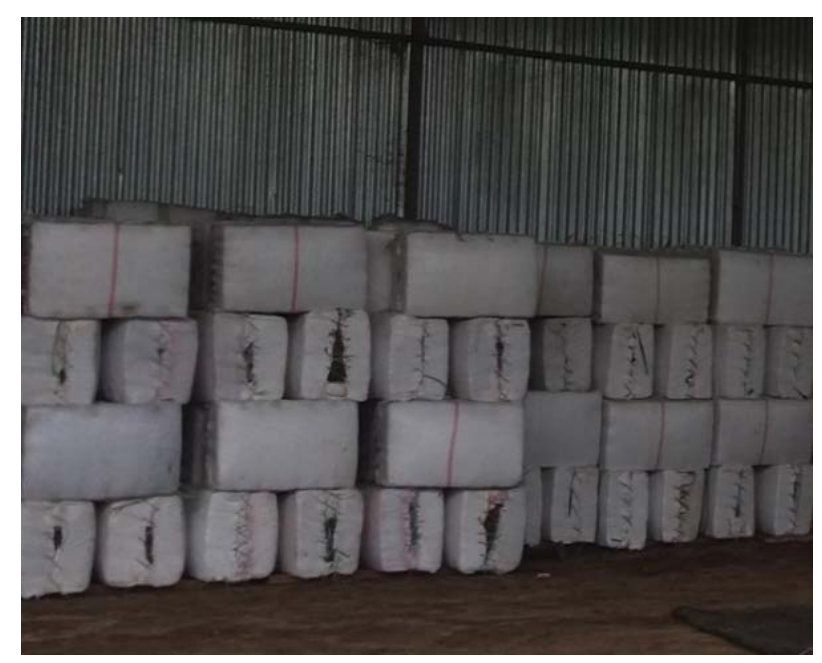

Gambar 9. Sebelum Penataan Palet

c. Pemberian garis batas antar stasiun untuk mengorganisir area gudang sehinga tertata rapi dan terdapat pembedaan antar stasiun. Contoh beberapa hasil dokumentasi dapat dilihat pada Gambar 11 sampai dengan Gambar 14.

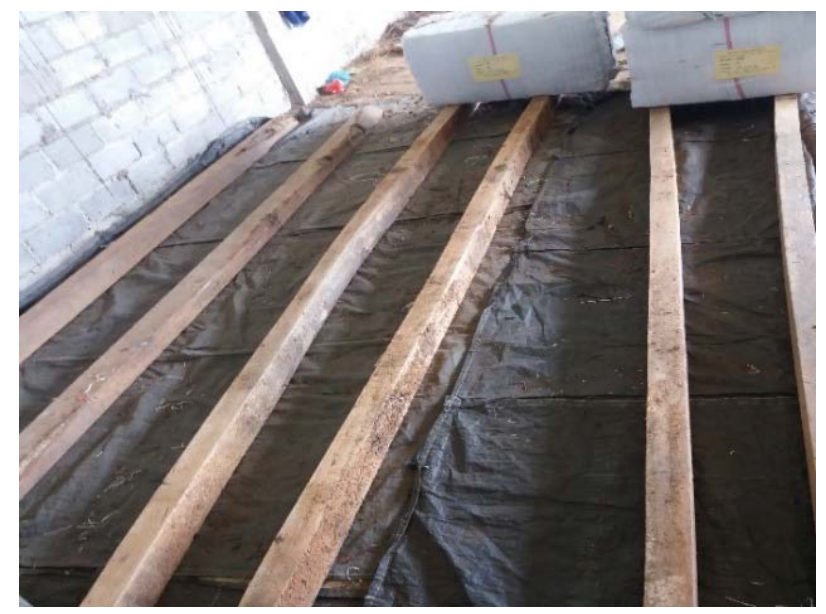

Gambar 10. Sesudah Penataan Palet

1) Stasiun Packing dan Mixing

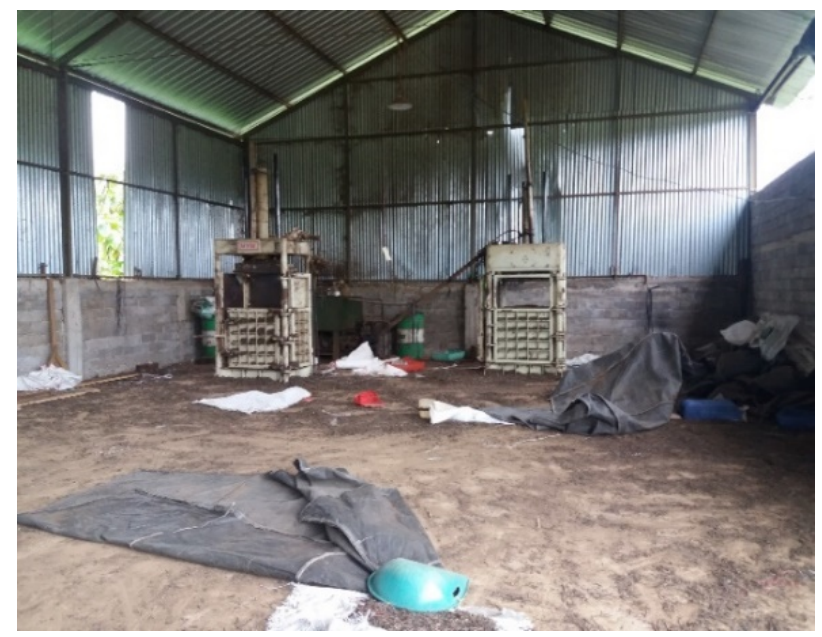

Gambar 11. Sebelum Pemberian Garis Batas pada Stasiun Mixing dan Packing

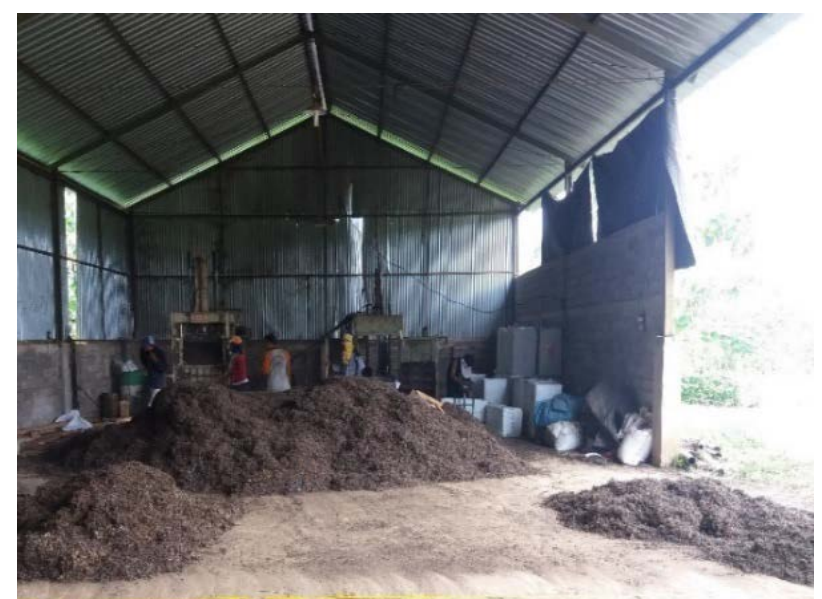

Gambar 12. Sesudah Pemberian Garis Batas pada Stasiun Mixing dan Packing 
2) Stasiun Penyimpanan Bahan Baku

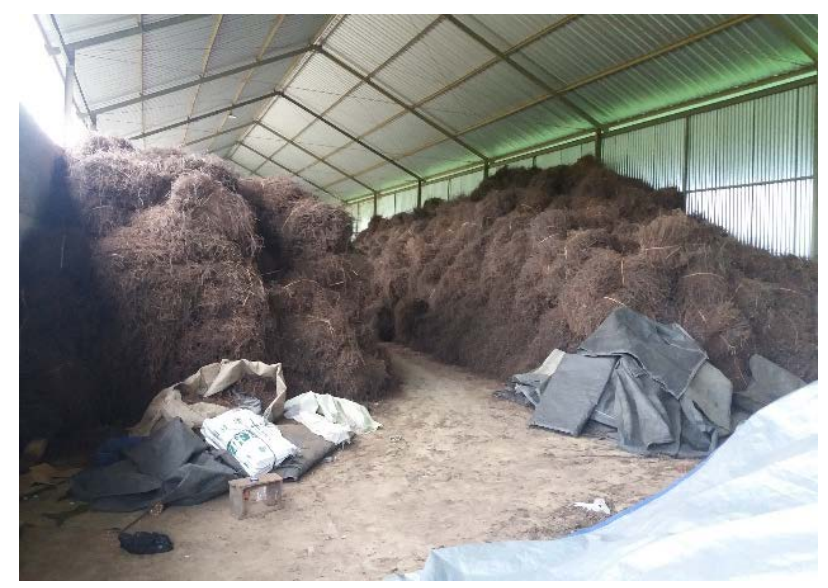

Gambar 13. Sebelum Pemberian Garis Batas

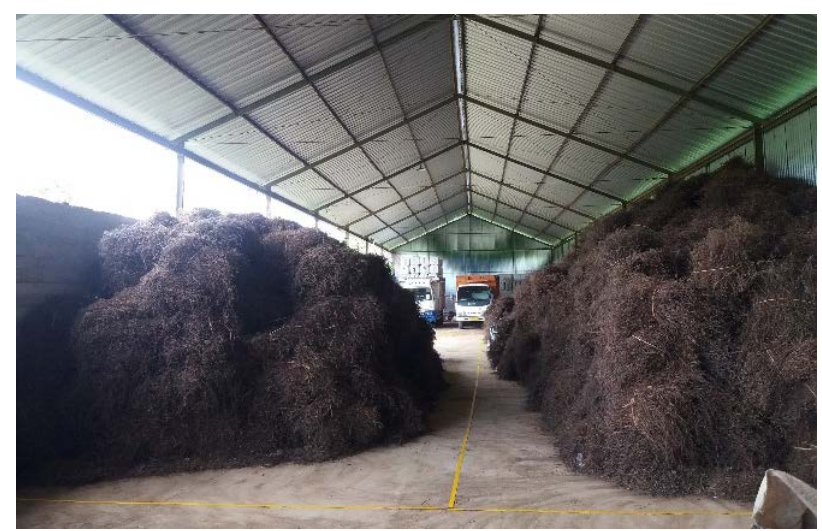

Gambar 14. Sesudah Pemberian Garis Batas

d. Perbaikan layout gudang produk jadi untuk mempermudah aliran pergerakan atau pemindahan produk belum sesuai $100 \%$ dengan usulan perbaikan, karena kendala pemindahan bahan baku dan produk jadi yang jumlahnya sangat besar.

\section{Seiso (Resik)}

Perbaikan pada tahap Seiso yaitu melakukan kegiatan kebersihan di tempat kerja setiap saat agar tetap rapi dan nyaman bagi seluruh pekerja. Setelah penerapan ketiga tahap 3S (Seiri, Seiton, dan Seiso) kemudian dilakukan perawatan (Seiketsu) dan Shitsuke (Rajin) untuk memelihara dan memantau agar 3S yang sudah diterapkan berjalan sesuai dengan peraturan yang telah ditetapkan. Untuk menjaga ketertiban dalam pelaksanaan 3S dilakukan inspeksi secara rutin, dari 3 kali inspeksi yang dilakukan didapatkan penurunan temuan ketidaksesuaian yang terjadi dalam gudang, pada inspeksi terakhir didapatkan temuan yang tidak sesuai sebanyak 3 macam. Temuan mengalami penurunan yang cukup signifikan dibanding dengan temuan awal yaitu sebanyak 13 macam.

\section{Tahap Penilaian}

Pada tahap penilaian dilakukan dengan 2 cara yaitu yang pertama penilaian terhadap berjalannya penerapan $5 \mathrm{~S}$ melalui inspeksi oleh pemilik perusahaan dengan membandingkan hasil inspeksi yang dilakukan sebelum penerapan dan sesudah penerapan 5S. Dan yang kedua penilaian dengan melakukan pengukuran data waktu alur proses pada gudang. Hasil pengukuran ulang waktu dapat dilihat pada Tabel 5.

Dari Tabel 5 dapat dilihat terdapat pengurangan waktu setelah dilakukan penerapan 5S di gudang 2 yaitu sebanyak 3 jam 10 menit 35 detik. Hal ini menunjukkan bahwa dengan melakukan penerapan 5S dan perbaikan pada gudang 2 dapat meminimalisir atau menghilangkan waste yang terjadi di gudang 2 sehingga dapat mengurangi waktu yang tidak memiliki nilai tambah (non value added time).

Tabel 5. Perbandingan Sebelum dan Sesudah Penerapan 5S Pada Gudang 2

\begin{tabular}{|c|c|c|c|c|c|c|c|}
\hline \multirow[b]{2}{*}{ No } & \multirow[b]{2}{*}{ Alur Proses } & \multirow[b]{2}{*}{ Aktivitas } & \multicolumn{2}{|c|}{ Sebelum } & \multicolumn{2}{|c|}{ Sesudah } & \multirow[b]{2}{*}{ Selisih } \\
\hline & & & $\begin{array}{l}\text { Non Value } \\
\text { Added Time }\end{array}$ & $\begin{array}{l}\text { Value Added } \\
\text { Time }\end{array}$ & $\begin{array}{l}\text { Non Value } \\
\text { Added Time }\end{array}$ & $\begin{array}{l}\text { Value Added } \\
\text { Time }\end{array}$ & \\
\hline \multirow[t]{4}{*}{1} & \multirow{4}{*}{$\begin{array}{l}\text { Picking \& } \\
\text { shorting } \\
\text { janggelan } \\
\text { kering }\end{array}$} & $\begin{array}{l}\text { Pemisahan rumput atau } \\
\text { kotoran pada bahan baku }\end{array}$ & - & $1 \mathrm{~h} 2$ mins & - & $\begin{array}{l}54 \text { mins } \\
26 \text { det }\end{array}$ & $\begin{array}{c}7 \text { mins } \\
9 \text { det }\end{array}$ \\
\hline & & Pencacahan bahan baku & - & 4 h 3 mins & - & $4 \mathrm{~h} 3$ mins & - \\
\hline & & $\begin{array}{l}\text { Pengisian bahan baku pada } \\
\text { cetakan }\end{array}$ & - & $\begin{array}{l}42 \mathrm{mins} \\
21 \mathrm{det}\end{array}$ & - & $\begin{array}{l}42 \text { mins } \\
21 \text { det }\end{array}$ & - \\
\hline & & $\begin{array}{l}\text { Pemindahan cetakan ke } \\
\text { mesin packing }\end{array}$ & - & $\begin{array}{c}23 \text { mins } \\
13 \text { det }\end{array}$ & - & $\begin{array}{c}23 \text { mins } \\
13 \text { det }\end{array}$ & - \\
\hline
\end{tabular}


Lanjutan Tabel 5. Perbandingan Sebelum dan Sesudah Penerapan 5S pada Gudang 2

\begin{tabular}{|c|c|c|c|c|c|c|c|}
\hline \multirow[b]{2}{*}{ No } & \multirow[b]{2}{*}{ Alur Proses } & \multirow[b]{2}{*}{ Aktivitas } & \multicolumn{2}{|c|}{ Sebelum } & \multicolumn{2}{|c|}{ Sesudah } & \multirow[b]{2}{*}{ Selisih } \\
\hline & & & $\begin{array}{c}\text { Non Value } \\
\text { Added Time }\end{array}$ & $\begin{array}{l}\text { Value Added } \\
\text { Time }\end{array}$ & $\begin{array}{l}\text { Non Value } \\
\text { Added Time }\end{array}$ & $\begin{array}{l}\text { Value Added } \\
\text { Time }\end{array}$ & \\
\hline & & $\begin{array}{l}\text { Pengembalian cetakan ke } \\
\text { stasiun packing }\end{array}$ & - & 4 mins 6 det & - & 4 mins 6 det & - \\
\hline \multirow[t]{3}{*}{2} & \multirow[t]{3}{*}{$\begin{array}{l}\text { Proses } \\
\text { packing }\end{array}$} & $\begin{array}{l}\text { Penempatan cetakan pada } \\
\text { mesin packing }\end{array}$ & - & 7 mins 51 det & - & 7 mins 51 det & - \\
\hline & & Packing & - & 7h 23 mins & - & 7h 23 mins & - \\
\hline & & $\begin{array}{l}\text { Pemindahan dari mesin } \\
\text { packing ke alat penimbang }\end{array}$ & - & $\begin{array}{c}34 \text { mins } \\
10 \text { det }\end{array}$ & - & $\begin{array}{c}34 \text { mins } \\
10 \text { det }\end{array}$ & - \\
\hline \multirow[t]{2}{*}{3} & \multirow{2}{*}{$\begin{array}{l}\text { Inspeksi } \\
\text { berat produk } \\
\text { jadi }\end{array}$} & $\begin{array}{l}\text { Inspeksi (penimbangan) } \\
\text { berat janggelan }\end{array}$ & - & 40 mins 5 det & - & 40 mins 5 det & - \\
\hline & & $\begin{array}{l}\text { pemindahan dari timbangan } \\
\text { ke tempat penyimpanan }\end{array}$ & - & $51 \mathrm{~min} 41$ det & - & $47 \mathrm{~min} 18$ det & $\begin{array}{l}4 \text { mins } \\
23 \text { det }\end{array}$ \\
\hline \multirow[t]{2}{*}{4} & \multirow{2}{*}{$\begin{array}{l}\text { Proses } \\
\text { penyimpanan } \\
\text { (Storage) }\end{array}$} & $\begin{array}{l}\text { Penataan produk jadi dalam } \\
\text { gudang penyimpanan }\end{array}$ & - & $\begin{array}{l}40 \text { mins } \\
14 \text { det }\end{array}$ & - & $\begin{array}{l}40 \mathrm{mins} \\
14 \mathrm{sec}\end{array}$ & - \\
\hline & & $\begin{array}{l}\text { Penyimpanan produk jadi } \\
\text { hingga di kirim }\end{array}$ & 1h 19 mins & 4 days & - & 4 days & $\begin{array}{c}1 \mathrm{~h} \\
19 \mathrm{mins}\end{array}$ \\
\hline \multirow[t]{4}{*}{5} & \multirow[t]{4}{*}{$\begin{array}{l}\text { Pengiriman } \\
\text { produk jadi }\end{array}$} & $\begin{array}{l}\text { Pemindahan produk jadi ke } \\
\text { truk pengiriman }\end{array}$ & 57 mins 3 det & 2h 30 mins & $\begin{array}{l}6 \mathrm{mins} \\
37 \mathrm{sec}\end{array}$ & 2h 30 mins & $\begin{array}{c}50 \text { mins } \\
26 \text { det }\end{array}$ \\
\hline & & $\begin{array}{l}\text { Penataan produk jadi pada } \\
\text { truk pengiriman }\end{array}$ & $\begin{array}{l}53 \text { mins } \\
48 \text { det }\end{array}$ & 1h 42 mins & 4 mins $11 \mathrm{sec}$ & 1h 42 mins & $\begin{array}{l}49 \text { mins } \\
37 \text { det }\end{array}$ \\
\hline & & $\begin{array}{l}\text { Pemindahan produk jadi ke } \\
\text { kontainer pengiriman }\end{array}$ & & 5h 18 mins & & 5h 18 mins & - \\
\hline & & $\begin{array}{l}\text { Pengiriman produk jadi ke } \\
\text { konsumen }\end{array}$ & & & & & - \\
\hline & $\mathrm{J}$ & h pengurangan waktu & & & $3 \mathrm{~h} 10 \mathrm{mi}$ & let & \\
\hline
\end{tabular}

\section{KESIMPULAN}

Hasil analisis dari big picture mapping pada gudang 1 dan gudang 2 ditemukan beberapa pemborosan (waste) yang paling menonjol diantaranya yaitu waste transportasi, waste defects, waste over production, inappropriate processing, dan waste movement. Dari pembobotan yang dilakukan terhadap waste yang terjadi di gudang didapatkan pemborosan dengan bobot tertinggi di gudang 1 adalah over production sedangkan untuk gudang 2 adalah waste defects. Penyebab terjadinya over production diantaranya yaitu jumlah produksi yang tidak dibatasi, bahan baku janggelan yang musiman, tidak seimbangnya alur produksi. Pada gudang 2 waste defects disebabkan sistem FIFO yang tidak berjalan dengan baik, tidak adanya palet pada produk jadi, dan karung packing yang tidak tahan air. Berdasarkan penerapan 5S yang telah dilakukan diperoleh hasil yang cukup baik, dapat dilihat dari hasil inspeksi terdapat pengurangan temuan ketidaksesuaian dari kategori red sebanyak 13 temuan menjadi white sebanyak 3 temuan. Dilakukan pengukuran ulang waktu alur proses di gudang 2 setelah penerapan 5S didapatkan pengurangan waktu sebesar 3 jam 10 menit 35 detik.

\section{DAFTAR PUSTAKA}

[1] Mulcahy, D.E., 1994, Warehouse and Distribution Operation Handbook International Edition, McGraw Hill, New York.

[2] Gergova, Iva, 2010, Warehouse Improvement with Lean 5S A Case Study of Ulstein Verft AS, Associated Professor Bjorn Guvag.

[3] Hines, Peter and Taylor, David, 2000, Going Lean, Lean Enterprises Research Center Cardiff Business School, USA.

[4] Barros, T.R., 2015, Applying value stream mapping as promotion of lean manufacturing in a warehouse of automative replacement parts in the search for greater competitiveness, Int. J. Business Performance and Supply Chain Modelling, Vol. 7, No. 2, PP. 109-121.

[5] Purnomo, M. P. dan Bisono, I., 2014, Identifikasi Waste dengan Menggunakan Value Stream Mapping dan Upaya 
Penerapan Lean Warehouse pada Gudang Produk Jadi CV. Bumi Makmur, Karang Tengah, Wonogiri

untuk Meminimasi Pemborosan

Ida Nursanti dan Febriana Musfiroh

Perbaikan Kinerja di Gudang PT. Y. Jurnal Titra, Vol. 2, No. 2, PP. 7-14.

[6] Chen, J. C., dkk., 2013, Warehouse management with lean and RFID application: a case study, Int J Adv Manuf Technol. DOI 10.1007/s00170013-5016-8, Springer-Verlag London.

[7] Sharma, S. dan Shah, B., 2015, A proposed hybrid storage assignment framework: a case study, International
Journal of Productivity and Performance Management Vol. 64, No. 6, PP. 870-892, Emerald Group Publishing Limited.

[8] Intifada, G. S., dan Wityanto., 2012, Minimasi Waste (Pemborosan) Menggunakan Value Stream Analysis Tool untuk Meningkatkan Efisiensi Waktu Produksi, Jurnal Teknik POMITS, Vol. 1, No. 1. 